\title{
hOGG1 gene polymorphisms and susceptibility to polycystic ovary syndrome
}

\author{
YANJIE XIA ${ }^{1,2}$, WENQING WANG $^{2}$, LEI WANG $^{2}$, SHANMEI SHEN $^{3}$, \\ $\mathrm{YUNXIACAO}^{4}, \mathrm{LONG} \mathrm{YI}^{2}$, QIAN GAO ${ }^{2}$ and YONG WANG ${ }^{2}$
}

\begin{abstract}
${ }^{1}$ Center of Prenatal Diagnosis, The First Affiliated Hospital of Zhengzhou University, Zhengzhou, Henan 450052; ${ }^{2}$ Center for Translational Medicine and Jiangsu Key Laboratory of Molecular Medicine, Medical School of Nanjing University; ${ }^{3}$ Nanjing Drum Tower Hospital, The Affiliated Hospital of Medical School of Nanjing University, Nanjing, Jiangsu 210093;

${ }^{4}$ Department of Obstetrics and Gynecology, Anhui Medical University, Hefei, Anhui 230022, P.R. China
\end{abstract}

Received February 13, 2015; Accepted February 4, 2016

DOI: $10.3892 /$ br.2016.600

\begin{abstract}
Oxidative stress generates 8-hydroxy-2'-deoxyguanine (8-oxodG), which can structurally modify DNA. Glycosylase hOGG1 can remove the mutagenic lesion 8-oxodG from DNA. The aim of the present study was to determine whether polymorphisms in hOGG1 were associated with the risk of polycystic ovary syndrome (PCOS). One common single-nucleotide polymorphism (Ser326Cys) in exon 7 and four rare polymorphisms (c. $-18 \mathrm{G}>\mathrm{T}$, c. $-23 \mathrm{~A}>\mathrm{G}$, c. $-45 \mathrm{G}>\mathrm{A}$ and c. $-53 \mathrm{G}>\mathrm{C}$ ) were screened in the 5 ' untranslated region of the $h O G G 1$ gene. No such distributional differences were observed between the PCOS patients and controls either in the genotype frequency or in the allele frequency. There were no differences in the clinical variables among the different genotypes in all the variants, except that the follicle-stimulating hormone level was elevated in the $\mathrm{GC}$ genotype of c. $-53 \mathrm{G}>\mathrm{C}$ in $\mathrm{PCOS}$ patients $(\mathrm{P}=0.002)$. These results suggest that the polymorphisms in $h O G G 1$ may not be an independent risk factor for PCOS.
\end{abstract}

\section{Introduction}

In the living cells of aerobic organisms, reactive oxygen species (ROS) are continuously produced in various physiological processes, such as metabolic and other biochemical reactions. A low level of ROS is essential for maintaining physiological function and biochemical pathway processing,

Correspondence to: Professor Yong Wang or Professor Qian Gao, Center for Translational Medicine and Jiangsu Key Laboratory of Molecular Medicine, Medical School of Nanjing University, 22 Hanjou Road, Nanjing, Jiangsu 210093, P.R. China

E-mail: yongwang@nju.edu.cn

E-mail: qian_gao@nju.edu.cn

Key words: polycystic ovary syndrome, genetic polymorphism, hOGG1, 5' untranslated region including intracellular signaling pathways in cell differentiation, proliferation, apoptosis (1) and immunity (2). By contrast, high levels of ROS can cause oxidative stress damaging biological macromolecules, such as membrane lipids, proteins and DNA, which may lead to metabolic malfunctions (3-5). 8-Hydroxy-2'-deoxyguanine (8-OHdG) induces ROS-mediated oxidative damage by promoting the transversion of $\mathrm{G} / \mathrm{C}$ to $\mathrm{A} / \mathrm{T}$, as it has a higher affinity for pairing with adenine (A) rather than cytosine (C) (6). Base excision repair (BER) of DNA reverses a number of spontaneous and environmentally induced genotoxic or miscoding base lesions in a process initiated by DNA glycosylases (7). Human OGG1 (hOGG1) efficiently repairs the incorrect or damaged bases by removing $8-\mathrm{OHdG}$, as part of the BER pathway (8).

Previous studies have reported several polymorphisms in the $h O G G 1$ gene $(9,10)$. In vitro activity assays confirmed that some of the variants affect hOGG1 expression resulting in a substantially higher DNA repair activity. Variants in the $h O G G l$ gene have been investigated in numerous diseases (11-13). A number of genetic variants in the $h O G G 1$ gene may alter the repair function and thus contribute to the development of ROS-related diseases.

PCOS is one of the most common reproductive endocrine disorders, affecting 5-10\% of women of reproductive age (14). PCOS is a heterogeneous syndrome characterized by clinical and/or biochemical androgen excess, polycystic ovaries and ovulatory dysfunction (15). While the etiology of PCOS remains to be elucidated, accumulating evidence suggests that chronic low-grade inflammation strengthens the development of metabolic aberration and ovarian dysfunction in this disorder $(16,17)$. Circulating TNF- $\alpha$ levels are elevated in PCOS patients (18). TNF- $\alpha$ is mainly derived from mononuclear cells (MNCs), and hyperglycemia can further induce MNCs to produce TNF- $\alpha$ and ROS $(18,19)$. TNF- $\alpha$ and ROS in turn exacerbate the inflammatory process, resulting in chronic inflammation in PCOS patients. The hOGGl gene is associated with decreased insulin sensitivity (20), a common feature of certain PCOS patients. Therefore, we hypothesize that a link between the hOGGl gene and PCOS may exist. 
Table I. Clinical and endocrine characteristics of PCOS patients and controls.

\begin{tabular}{lccccccrr}
\hline Patients & Total, $\mathrm{n}$ & Age, years & BMI $^{\mathrm{a}}, \mathrm{kg} / \mathrm{m}^{2}$ & $\mathrm{FSH}^{\mathrm{a}}, \mathrm{IU} / \mathrm{l}$ & $\mathrm{LH}^{\mathrm{a}}, \mathrm{IU} / \mathrm{l}$ & $\mathrm{LH} / \mathrm{FSH}^{\mathrm{a}}$ & $\mathrm{E}^{\mathrm{a}}, \mathrm{pg} / \mathrm{ml}$ & $\mathrm{T}^{\mathrm{a}}, \mathrm{nmol}^{\prime} /$ \\
\hline Control & 440 & $33.02 \pm 5.39$ & $21.95 \pm 3.91$ & $8.36 \pm 8.32$ & $5.62 \pm 4.86$ & $0.75 \pm 0.50$ & $65.33 \pm 58.40$ & $2.45 \pm 1.75$ \\
PCOS & 425 & $26.95 \pm 6.79$ & $22.96 \pm 6.13$ & $5.97 \pm 3.22$ & $11.77 \pm 8.96$ & $2.26 \pm 3.04$ & $79.3 \pm 69.22$ & $2.7 \pm 6.02$ \\
\hline
\end{tabular}

${ }^{\mathrm{a}} \mathrm{P}<0.05$ between the PCOS and control groups. Data are mean \pm standard deviation. BMI, body mass index; FSH, follicle-stimulating hormone; LH, luteinizing hormone; E2, estradiol; T, testosterone; PCOS, polycystic ovary syndrome.

\section{Materials and methods}

Subjects. A total of 865 individuals, consisting of 425 PCOS patients and 440 non-PCOS control women, were involved in the present study. All the participants were of Han Chinese origin. Peripheral venous blood samples were collected at Nanjing Drum Tower Hospital of Nanjing University, Memorial Hospital of Sun Yat-Sen University (Nanjing, Jiangsu, China), and at the Department of Obstetrics and Gynecology of Anhui Medical University (Hefei, Anhui, China) between 2004 and 2013. The PCOS patients were diagnosed based on the 2003 Rotterdam Criteria (15). All the controls had normal ovulatory menstrual cycles and did not show hirsutism or other manifestations of hyperandrogenism. Serum hormone levels and clinical variables [including age and body mass index (BMI)] were measured as previously described (21). The study was approved by the Ethics Committee of Nanjing University and informed consent was obtained from each participant.

Polymorphism genotyping analysis in the hOGGl gene. Genomic DNA was isolated from peripheral blood leukocytes using an UltraPure ${ }^{\mathrm{TM}}$ Genome DNA kit (SBS Genetech Co., Ltd., Shanghai, China) and stored at $-80^{\circ} \mathrm{C}$. A DNA fragment containing part of the $5^{\prime}$ untranslated region (UTR) and the full region of exon 1 was amplified with the primers: Forward, 5'-AGG AGG TGG AGG AAT TAA GT-3' and reverse, 5'-GGC TTC TCA GGC TCA GTC A-3', as described previously $(9,11)$. Amplification of DNA sequences, including Ser326Cys polymorphism in exon 7, was carried out with: Forward primer, 5'-GGA AGG TGC TTG GGG AAT-3' and reverse primer, 5'-ACT GTC ACT AGT CTC ACC AG-3'. Polymorphism chain reaction (PCR) was run in a total volume of $25 \mu \mathrm{l}$ containing $50 \mathrm{ng}$ of genomic DNA, 6 pmol of each primer, $2.5 \mu 1$ short tandem repeat 10X buffer (Promega, Madison, WI, USA) and 0.75 units of GoTaq DNA polymerase (Promega). The PCR protocol was conducted as follows: Denaturing at $95^{\circ} \mathrm{C}$ for $5 \mathrm{~min}$, followed by 30 cycles consisting of $30 \mathrm{sec}$ of denaturation at $94^{\circ} \mathrm{C}, 30 \mathrm{sec}$ of annealing at $60^{\circ} \mathrm{C}$ for $5^{\prime}$-UTR or $58^{\circ} \mathrm{C}$ for exon 7 , and $30 \mathrm{sec}$ of extension at $72^{\circ} \mathrm{C}$; and a final single extension of $10 \mathrm{~min}$ at $72^{\circ} \mathrm{C}$. For $5^{\prime}-\mathrm{UTR}$, the genotyping was carried out by direct sequencing on an ABI 3130 automated sequencer at Nanjing Springen Bio-Technique Corp. (Nanjing, China). Genotyping for the hOGG1 Ser326Cys polymorphism was performed by the PCR-restriction fragment length polymorphism (RFLP) assay. Briefly, a 200-base pair (bp) PCR product was digested at $37^{\circ} \mathrm{C}$ with Fnu4HI (Thermo Fisher Scientific, Inc., San
Jose, CA, USA) for $16 \mathrm{~h}$ resulting in a single 200-bp band for the homozygous Ser/Ser hOGG1 variant, a single 100-bp band for the homozygous Cys/Cys hOGGl variant, and double bands of 200 and 100 bp for the heterozygous Ser/Cys hOGGl variant. Digestion was visualized following electrophoresis on a 3\% agarose gel containing ethidium bromide. Finally, 100 DNA samples were randomly selected for direct sequence to validate Ser326Cys.

Serum hormone determination. Venous blood samples were collected in the early follicular phase (days 3-5) of the menstrual cycle for those who had menstrual cycles and at any time for those who were amenorrheic. Prior to sample collection, all participants went through a 12 -h overnight fast. Serum estradiol (E2), testosterone (T), luteinizing hormone (LH) and follicle-stimulating hormone (FSH) were determined by radioimmunoassay (Beijing North Institute of Biological Technology of China, Beijing, China and the CIS Company of France, Gif-sur-Yvette, France). The intra-assay and inter-assay coefficients of variation were $<10 \%$ for all the assays.

Statistical analysis. Fisher's exact test or $\chi^{2}$ test was used when appropriate to detect the association between genotypic variants in the hOGGl gene. The PCOS risks were determined by the odds ratio (OR) and its corresponding 95\% confidence intervals (CIs). Genotype frequencies for each single-nucleotide polymorphism (SNP) were determined for Hardy-Weinberg equilibrium in the control group. The results of serum hormone levels, age and BMI are reported as the mean \pm standard deviation. Genotypic distribution analysis between PCOS and control was carried out by Fisher's exact test. Biochemical steroid levels among different genotypes were compared by analysis of covariance to correct for age and BMI. All the statistical analysis was performed using the statistical program SPSS version 17.0 (SPSS, Inc., Chicago, IL, USA). $\mathrm{P}<0.05$ was considered to indicate a statistically significant difference.

\section{Results}

Clinical characteristics of PCOS and control subjects. Clinical variables and serum steroid hormone levels were compared between women with PCOS and controls (Table I). PCOS patients had significantly higher BMI, testosterone levels and LH/FSH ratios as compared with healthy control women.

Distribution of the hOGG1 gene variants. Five variants were screened in a case-control study that included 425 PCOS 
Table II. Germline $h O G G 1$ variations and genotype/allele frequencies in the case-control study.

\begin{tabular}{|c|c|c|c|c|c|}
\hline \multirow[b]{2}{*}{ SNP sites } & \multirow[b]{2}{*}{ Genotype/allele } & \multicolumn{2}{|c|}{ Total, n (\%) } & \multirow[b]{2}{*}{ P-value } & \multirow[b]{2}{*}{ OR $(95 \% \mathrm{CI})^{\mathrm{b}}$} \\
\hline & & $\operatorname{PCOS}(n=425)$ & Control $(n=440)$ & & \\
\hline \multirow[t]{4}{*}{ c. $-53 \mathrm{G}>\mathrm{C}$} & $\mathrm{GC}$ & $10(2.4)$ & $5(1.1)$ & 0.199 & $2.096(0.711-6.185)$ \\
\hline & GG & $415(97.6)$ & $435(98.9)$ & & 1 \\
\hline & $\mathrm{C}$ & $10(1.2)$ & $5(0.6)$ & 0.201 & $2.083(0.709-6.121)$ \\
\hline & G & $840(98.8)$ & $875(99.4)$ & & 1 \\
\hline \multirow[t]{4}{*}{ c. $-45 \mathrm{G}>\mathrm{A}$} & GA & $0(0.0)$ & $2(0.4)$ & 0.500 & - \\
\hline & GG & $425(100.0)$ & 438 (99.6) & & - \\
\hline & $\mathrm{A}$ & $0(0.0)$ & $2(0.2)$ & 0.500 & - \\
\hline & G & $850(100.0)$ & $878(99.8)$ & & - \\
\hline \multirow[t]{4}{*}{ c. $-23 \mathrm{~A}>\mathrm{G}$} & $\mathrm{AG}$ & $7(1.6)$ & $14(3.2)$ & 0.185 & $0.510(0.204-1.275)$ \\
\hline & AA & $418(98.4)$ & $426(96.8)$ & & 1 \\
\hline & $\mathrm{G}$ & $7(0.8)$ & $14(1.6)$ & 0.188 & $0.514(0.206-1.279)$ \\
\hline & A & $843(99.2)$ & $866(98.4)$ & & 1 \\
\hline \multirow[t]{4}{*}{ c. $-18 \mathrm{G}>\mathrm{T}$} & GT & $13(3.0)$ & $20(4.5)$ & 0.289 & $0.663(0.325-1.350)$ \\
\hline & GG & $412(97.0)$ & $420(95.5)$ & & 1 \\
\hline & $\mathrm{T}$ & $13(1.5)$ & $20(2.3)$ & 0.294 & $0.668(0.330-1.351)$ \\
\hline & $\mathrm{G}$ & $837(98.5)$ & $860(97.7)$ & & 1 \\
\hline \multirow{5}{*}{$\begin{array}{l}\text { Ser326Cys } \\
(\mathrm{C}>\mathrm{G})\end{array}$} & GG & $156(36.7)$ & $141(32.0)$ & & $1.314(0.878-1.966)$ \\
\hline & $\mathrm{CG}$ & $205(48.2)$ & $223(50.7)$ & 0.319 & $1.092(0.744-1.601)$ \\
\hline & $\mathrm{CC}$ & $64(15.1)$ & $76(17.3)$ & & 1 \\
\hline & G & $517(60.8)$ & $505(57.4)$ & 0.146 & $1.153(0.952-1.397)$ \\
\hline & $\mathrm{C}$ & $333(39.2)$ & $375(42.6)$ & & 1 \\
\hline
\end{tabular}

${ }^{a}$ Data were analyzed for the frequencies of genotypes or alleles between cases and controls carried out by Fisher's exact test. ${ }^{\mathrm{b} O R}$ (95\% CI) were calculated as the wild genotype. SNP, single-nucleotide polymorphism; PCOS, polycystic ovary syndrome; OR, odds ratio; CI, confidence interval.

A

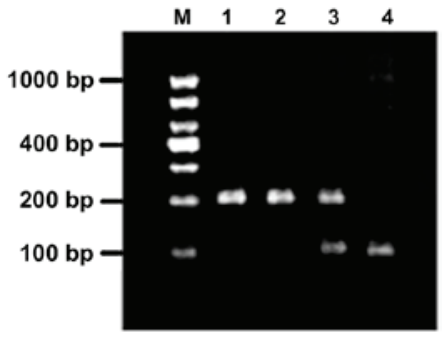

B

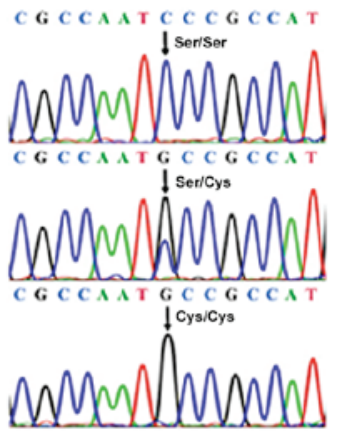

Figure 1. Analyses of the $h O G G 1$ polymorphism chain reaction products following digestion with $F n u 4 \mathrm{HI}$ by direct sequencing. (A) Identification of different genotypes of $h O G G 1$ Ser326Cys polymorphisms by electrophoresis of DNA fragments. M, molecular weight marker; lane 1, PCR product without digestion; lane 2, genotype Ser/Ser; lane 3, genotype Ser/Cys; lane 4, genotype Cys/Cys. (B) The Ser326Cys genotypes were identified by DNA direct sequencing. The Ser/Ser, Ser/Cys and Cys/Cys genotypes are indicated by arrows. patients and 440 age-matched controls by direct sequencing and/or RFLP (Fig. 1A and B). Four of the variants were SNP, namely, c. $-18 \mathrm{G}>\mathrm{T}$, c. $-23 \mathrm{~A}>\mathrm{G}$, c. $-53 \mathrm{G}>\mathrm{C}$ and Ser326Cys. The genotypic distributions of the four SNPs were consistent with Hardy-Weinberg equilibrium in the control group. A rare variation, c. $-45 \mathrm{G}>\mathrm{A}$, was only observed in the normal controls with an extremely low allele frequency $(<1 \%)$, while another previously reported rare variation, c.-63G $>C$, was not detected in the Chinese population examined in the present study. Of note, the four closely adjacent variants did not appear to belong to an individual linkage disequilibrium block, as there were no combined variants in the whole population investigated.

No significant differences were detected in the genotype frequency or allele frequency in all five variations between patients and control (Table II). There were no differences in the clinical variables and hormone levels among the different genotypes in all the variants, except that the FSH level was elevated in the GC genotype $(\mathrm{P}=0.002)$ of $\mathrm{c} .-53 \mathrm{G}>\mathrm{C}$ in PCOS patients (Tables III-VII). Furthermore, the potential joint effect between the four rare variants and Ser326Cys was investigated to evaluate the risk of the combined variants in PCOS. However, no significant association was found in each individual allele (Table II) or genotype combinations (data not shown). 
Table III. Comparisons of variants at c.-53 G>C for women with or without PCOS in terms of anthropometric characteristics and serum hormone concentrations.

\begin{tabular}{|c|c|c|c|c|c|c|}
\hline \multirow[b]{2}{*}{ Genotypes } & \multicolumn{2}{|c|}{ Control } & \multirow[b]{2}{*}{ P-value } & \multicolumn{2}{|c|}{ PCOS } & \multirow[b]{2}{*}{ P-value } \\
\hline & $G G$ & $G C$ & & $G G$ & $G C$ & \\
\hline Age, years & $32.99 \pm 5.35$ & $36.67 \pm 10.40$ & 0.240 & $26.89 \pm 6.73$ & $29.33 \pm 9.35$ & 0.384 \\
\hline $\mathrm{BMI}, \mathrm{kg} / \mathrm{m}^{2}$ & $21.95 \pm 3.92$ & $21.54 \pm 1.46$ & 0.856 & $22.96 \pm 6.17$ & $22.97 \pm 4.83$ & 0.994 \\
\hline FSH, IU/1 & $8.33 \pm 8.33$ & $11.75 \pm 7.98$ & 0.480 & $5.86 \pm 2.77$ & $10.36 \pm 11.51$ & $0.002^{\mathrm{a}}$ \\
\hline LH, IU/1 & $5.63 \pm 4.88$ & $4.97 \pm 1.79$ & 0.815 & $11.72 \pm 9.04$ & $14.08 \pm 4.66$ & 0.562 \\
\hline LH/FSH & $0.75 \pm 0.50$ & $0.48 \pm 0.13$ & 0.356 & $2.26 \pm 3.07$ & $2.17 \pm 0.99$ & 0.947 \\
\hline $\mathrm{T}, \mathrm{nmol} / \mathrm{l}$ & $2.46 \pm 1.74$ & $0.24 \pm 0$ & 0.207 & $2.70 \pm 6.09$ & $2.49 \pm 1.16$ & 0.938 \\
\hline $\mathrm{E} 2, \mathrm{pg} / \mathrm{ml}$ & $65.68 \pm 58.51$ & $26.83 \pm 27.25$ & 0.252 & $79.18 \pm 69.64$ & $84.35 \pm 55.60$ & 0.869 \\
\hline
\end{tabular}

${ }^{\mathrm{a}} \mathrm{P}<0.05$. Statistical analyses were carried out by analysis of covariance to correct for age and BMI. Data are mean \pm standard deviation. BMI, body mass index; FSH, follicle-stimulating hormone; LH, luteinizing hormone; E2, estradiol; T, testosterone.

Table IV. Comparisons of variants at c.-45 G>A for women without PCOS in terms of anthropometric characteristics and serum hormone concentrations.

\begin{tabular}{lccc}
\hline & \multicolumn{2}{c}{ Control } \\
\cline { 2 - 3 } Genotypes & $G G$ & $A G$ & P-value \\
\hline Age, years & $32.92 \pm 5.68$ & $33.00 \pm 5.65$ & 0.987 \\
BMI, kg/m & $22.11 \pm 3.57$ & $20.45 \pm 0.64$ & 0.512 \\
FSH, IU/L & $8.37 \pm 8.35$ & $7.09 \pm 2.11$ & 0.829 \\
LH, IU/L & $5.62 \pm 4.86$ & $7.24 \pm 6.36$ & 0.638 \\
LH/FSH & $0.75 \pm 0.92$ & $0.50 \pm 0.62$ & 0.613 \\
T, nmol/l & $2.45 \pm 1.75$ & - & - \\
E2, pg/ml & $65.52 \pm 58.52$ & $34.00 \pm 14.14$ & 0.448 \\
\hline
\end{tabular}

Statistical analyses were carried out by analysis of covariance to correct for age and BMI. Data are mean \pm standard deviation. BMI, body mass index; FSH, follicle-stimulating hormone; LH, luteinizing hormone; E2, estradiol; T, testosterone.

\section{Discussion}

PCOS is a complex endocrine disease with no clear etiology. Accumulating evidence suggests that genetic and environmental factors contribute to its occurrence and development (22). Familial clustering of PCOS or PCOS-related metabolic symptoms indicates a genetic origin $(23,24)$, although no consensus of the inheritance mode has been reached. To date, significant attention has been focused on the genes involved in the androgen biosynthetic pathways (CYP11, CYP17 and CYP19) and insulin-related pathways (INS and $I N S R)$. However, other genes that are crucial in maintaining normal metabolic functions, such as insulin sensitivity preservation may show a link with this metabolic disease. The $h O G G 1$ gene is critical in BER. Several polymorphisms in hOGGl have been identified as associated with insulin sensitivity and type 2 diabetes mellitus (T2MD). The underlying role of ROS-induced oxidative stress in PCOS together with the correlation between ROS and the BER system provide us with a new insight into the possible causes of PCOS. To the best of our knowledge, this is the first time that functional polymorphisms in the hOGGl gene in Chinese PCOS patients have been investigated.

The structure and functions of hOGG1 have been well studied and several of its polymorphisms have been identified. Specifically, certain polymorphisms in hOGGl that are associated with insulin sensitivity or T2MD have been reported, indicating the functional involvement of hOGGl in the maintenance of normal glucose metabolism $(9,20,25)$. Previous studies have reported an association between oxidative stress and insulin resistance not only in the context of diabetes, but also in nondiabetic individuals and in those with metabolic syndromes (26-28). Consequently, increased generation of ROS in response to oxidative stress in metabolic syndromes prompted other investigators to focus on genomic instability and DNA damage that are associated with $h O G G 1$.

The present study investigated four rare SNPs in 5'-UTR and a common SNP (Ser326Cys) in exon 7 of the hOGGl gene in a case-control study of PCOS. The 5'-UTR region is known to modulate gene expression at the post-transcriptional level by influencing mRNA stability and translational efficiency medicated by transcription factors (TF) $(29,30)$. The inactivation or induction of the corresponding TF can modulate the expression of the $h O G G 1$ gene, thus influencing the activity of the protein $(31,32)$. Previous studies revealed that certain types of functional variants in the 5'-UTR of the hOGGl gene are capable of increasing the risks of diseases, including cancer $(9,11,33,34)$. The present finding suggests that there was no significant correlation between the variants in $h O G G l$ and the PCOS risk. Although the FSH level was elevated in the GC genotype of c. $-53 \mathrm{G}>\mathrm{C}$ in PCOS patients, it is difficult to provide any reasonable explanation for this phenomenon. The polymorphism Ser326Cys in the hOGG1 gene is shown to be associated with OGG1 activity in in vitro and in vivo studies, and it is suggested that the 326Cys allele may pose a higher risk of 8 -oxoG formation in DNA $(35,36)$. The associations between the $h O G G 1$ Ser326Cys polymorphism and various diseases have been extensively investigated. 
Table V. Comparisons of variants at c.-23 A $>$ G for women with or without PCOS in terms of anthropometric characteristics and serum hormone concentrations.

\begin{tabular}{|c|c|c|c|c|c|c|}
\hline \multirow[b]{2}{*}{ Genotypes } & \multicolumn{2}{|c|}{ Control } & \multirow[b]{2}{*}{ P-value } & \multicolumn{2}{|c|}{ PCOS } & \multirow[b]{2}{*}{ P-value } \\
\hline & $A A$ & $A G$ & & $A A$ & $A G$ & \\
\hline Age, years & $31.95 \pm 7.82$ & $34.50 \pm 5.48$ & 0.307 & $26.98 \pm 6.59$ & $31.25 \pm 5.44$ & 0.199 \\
\hline BMI, $\mathrm{kg} / \mathrm{m}^{2}$ & $22.05 \pm 3.57$ & $22.70 \pm 3.22$ & 0.551 & $22.91 \pm 6.32$ & $20.17 \pm 2.08$ & 0.388 \\
\hline FSH, IU/l & $8.36 \pm 8.44$ & $8.19 \pm 2.69$ & 0.949 & $6.01 \pm 3.22$ & $5.31 \pm 2.24$ & 0.668 \\
\hline LH, IU/1 & $5.62 \pm 4.92$ & $5.63 \pm 2.32$ & 0.997 & $11.77 \pm 8.92$ & $14.57 \pm 11.63$ & 0.537 \\
\hline LH/FSH & $0.75 \pm 0.51$ & $0.75 \pm 0.34$ & 0.987 & $2.26 \pm 3.06$ & $2.83 \pm 2.19$ & 0.713 \\
\hline $\mathrm{T}, \mathrm{nmol} / \mathrm{l}$ & $2.47 \pm 1.77$ & $1.91 \pm 1.20$ & 0.446 & $2.51 \pm 5.40$ & $2.20 \pm 1.67$ & 0.921 \\
\hline $\mathrm{E} 2, \mathrm{pg} / \mathrm{ml}$ & $65.57 \pm 58.88$ & $57.39 \pm 41.52$ & 0.663 & $79.22 \pm 69.54$ & $52.86 \pm 13.52$ & 0.513 \\
\hline
\end{tabular}

Statistical analyses were carried out by analysis of covariance to correct for age and BMI. Data are mean \pm standard deviation, body mass index; FSH, follicle-stimulating hormone; LH, luteinizing hormone; E2, estradiol; T, testosterone.

Table VI. Comparisons of variants at c.-18 G>T for women with or without PCOS in terms of anthropometric characteristics and serum hormone concentrations.

\begin{tabular}{|c|c|c|c|c|c|c|}
\hline \multirow[b]{2}{*}{ Genotypes } & \multicolumn{2}{|c|}{ Control } & \multirow[b]{2}{*}{ P-value } & \multicolumn{2}{|c|}{ PCOS } & \multirow[b]{2}{*}{ P-value } \\
\hline & $G G$ & $T G$ & & $G G$ & $T G$ & \\
\hline Age, years & $32.88 \pm 5.94$ & $31.81 \pm 5.46$ & 0.480 & $27.18 \pm 6.31$ & $26.64 \pm 8.03$ & 0.782 \\
\hline BMI, $\mathrm{kg} / \mathrm{m}^{2}$ & $21.79 \pm 3.79$ & $21.67 \pm 2.81$ & 0.910 & $23.56 \pm 5.10$ & $22.64 \pm 2.78$ & 0.572 \\
\hline FSH, IU/1 & $8.43 \pm 8.49$ & $6.78 \pm 1.86$ & 0.469 & $5.98 \pm 3.23$ & $6.31 \pm 2.39$ & 0.763 \\
\hline LH, IU/1 & $5.66 \pm 4.74$ & $4.94 \pm 2.34$ & 0.488 & $11.88 \pm 9.00$ & $10.59 \pm 7.98$ & 0.673 \\
\hline LH/FSH & $0.75 \pm 0.51$ & $0.77 \pm 0.46$ & 0.851 & $2.30 \pm 3.10$ & $1.60 \pm 0.89$ & 0.500 \\
\hline $\mathrm{T}, \mathrm{nmol} / \mathrm{l}$ & $2.43 \pm 1.76$ & $2.92 \pm 1.10$ & 0.638 & $2.70 \pm 6.14$ & $2.88 \pm 1.63$ & 0.930 \\
\hline $\mathrm{E} 2, \mathrm{pg} / \mathrm{ml}$ & $65.80 \pm 58.32$ & $59.48 \pm 61.51$ & 0.693 & $80.39 \pm 69.75$ & $68.86 \pm 42.30$ & 0.665 \\
\hline
\end{tabular}

Statistical analyses were carried out by analysis of covariance to correct for age and BMI. Data are mean \pm standard deviation. BMI, body mass index; FSH, follicle-stimulating hormone; LH, luteinizing hormone; E2, estradiol; T, testosterone.

Table VII. Comparisons of Ser326Cys (C>G) for women with or without PCOS in terms of anthropometric characteristics and serum hormone concentrations.

\begin{tabular}{|c|c|c|c|c|c|c|c|c|}
\hline \multirow[b]{2}{*}{ Genotypes } & \multicolumn{3}{|c|}{ Control } & \multirow[b]{2}{*}{ P-value } & \multicolumn{3}{|c|}{ PCOS } & \multirow[b]{2}{*}{ P-value } \\
\hline & $C C$ & $C G$ & $G G$ & & $C C$ & $C G$ & $G G$ & \\
\hline Age, years & $31.48 \pm 2.65$ & $33.12 \pm 5.03$ & $35.88 \pm 5.64$ & 0.675 & $25.95 \pm 8.01$ & $28.13 \pm 4.03$ & $30.88 \pm 6.74$ & 0.468 \\
\hline BMI, kg/m² & $21.46 \pm 3.74$ & $21.99 \pm 2.33$ & $21.77 \pm 3.74$ & 0.897 & $22.56 \pm 5.66$ & $23.43 \pm 4.51$ & $22.78 \pm 3.78$ & 0.649 \\
\hline FSH, IU/1 & $7.79 \pm 7.49$ & $8.68 \pm 2.94$ & $8.29 \pm 4.47$ & 0.469 & $5.78 \pm 4.23$ & $6.13 \pm 4.46$ & $5.89 \pm 2.23$ & 0.657 \\
\hline LH, IU/1 & $5.67 \pm 4.74$ & $5.74 \pm 4.04$ & $4.96 \pm 3.74$ & 0.658 & $11.59 \pm 6.99$ & $12.84 \pm 9.00$ & $8.66 \pm 6.74$ & 0.371 \\
\hline LH/FSH & $0.78 \pm 0.16$ & $0.75 \pm 0.69$ & $0.74 \pm 0.23$ & 0.865 & $2.31 \pm 1.92$ & $2.27 \pm 1.03$ & $1.76 \pm 1.89$ & 0.582 \\
\hline $\mathrm{T}, \mathrm{nmol} / \mathrm{l}$ & $2.49 \pm 1.32$ & $2.32 \pm 0.19$ & $2.45 \pm 1.96$ & 0.618 & $2.80 \pm 1.64$ & $2.44 \pm 1.96$ & $2.68 \pm 1.87$ & 0.654 \\
\hline $\mathrm{E} 2, \mathrm{pg} / \mathrm{ml}$ & $59.90 \pm 41.59$ & $65.60 \pm 48.22$ & $66.81 \pm 48.73$ & 0.413 & $67.16 \pm 48.37$ & $77.80 \pm 58.11$ & $81.49 \pm 64.77$ & 0.200 \\
\hline
\end{tabular}

Statistical analyses were carried out by analysis of covariance to correct for age and BMI. Data are mean \pm standard deviation. BMI, body mass index; FSH, follicle-stimulating hormone; LH, luteinizing hormone; E2, estradiol; T testosterone.

However, conflicted results, even in the same disease, have been reported $(37,38)$. The present study does not support an association of this polymorphism with PCOS susceptibility. Given the low allele frequency of the variants in 5'-UTR of 
hOGG1, further studies with a larger sample size are required to confirm these findings.

In conclusion, $h O G G 1$ is not an independent risk factor for PCOS development, and no putative linkage to the syndrome could be established.

\section{Acknowledgements}

The authors are grateful to all the members who participated in the present study. This study was supported by grants from the National Natural Science Foundation of China (no. 81170541) and the Natural Basic Research Program of China (no. 973 program 2010CB 945103).

\section{References}

1. Ghosh $\mathrm{J}$ and Myers CE: Inhibition of arachidonate 5-lipoxygenase triggers massive apoptosis in human prostate cancer cells Proc Natl Acad Sci USA 95: 13182-13187, 1998.

2. Yin GY, Yin YF and He XF: Effect of zhuchun pill on immunity and endocrine function of elderly with kidney-yang deficiency. Zhongguo Zhong Xi Yi Jie He Za Zhi 15: 601-603, 1995 (In Chinese).

3. Stadtman ER and Berlett BS: Reactive oxygen-mediated protein oxidation in aging and disease. Drug Metab Rev 30: 225-243, 1998.

4. Chopra $S$ and Wallace HM: Induction of spermidine/spermine N1-acetyltransferase in human cancer cells in response to increased production of reactive oxygen species. Biochem Pharmacol 55: 1119-1123, 1998.

5. Wells PG, Kim PM, Laposa RR, Nicol CJ, Parman T and Winn LM: Oxidative damage in chemical teratogenesis. Mutat Res 396: 65-78, 1997.

6. Shibutani S, Takeshita M and Grollman AP: Insertion of specific bases during DNA synthesis past the oxidation-damaged base 8-oxodG. Nature 349: 431-434, 1991.

7. Krokan HE, Nilsen H, Skorpen F, Otterlei M and Slupphaug G: Base excision repair of DNA in mammalian cells. FEBS Lett 476: 73-77, 2000.

8. David SS, O'Shea VL and Kundu S: Base-excision repair of oxidative DNA damage. Nature 447: 941-950, 2007.

9. Sun C, Liu X, Zhang H, Guo W, Cai Z, Chen H, Zhang K, Zhu D and Wang Y: Functional polymorphism of $h O G G 1$ gene is associated with type 2 diabetes mellitus in Chinese population. Mol Cell Endocrinol 325: 128-134, 2010.

10. Kohno T, Shinmura K, Tosaka M, Tani M, Kim SR, Sugimura H, Nohmi T, Kasai H and Yokota J: Genetic polymorphisms and alternative splicing of the hOGG1 gene, that is involved in the repair of 8-hydroxyguanine in damaged DNA. Oncogene 16 3219-3225, 1998

11. Chen X, Wang J, Guo W, Liu X, Sun C, Cai Z, Fan Y and Wang Y: Two functional variations in 5'-UTR of hoGGl gene associated with the risk of breast cancer in Chinese. Breast Cancer Res Treat 127: 795-803, 2011.

12. Le Marchand L, Donlon T, Lum-Jones A, Seifried A and Wilkens LR: Association of the hOGG1 Ser326Cys polymorphism with lung cancer risk. Cancer Epidemiol Biomarkers Prev 11: 409-412, 2002

13. Coppedè F, Migheli F, Ceravolo R, Bregant E, Rocchi A Petrozzi L, Unti E, Lonigro R, Siciliano G and Migliore L: The hOGG1 Ser326Cys polymorphism and Huntington's disease. Toxicology 278: 199-203, 2010.

14. Ehrmann DA: Polycystic ovary syndrome. N Engl J Med 352: 1223-1236, 2005.

15. Rotterdam ESHRE/ASRM-Sponsored PCOS consensus workshop group: Revised 2003 consensus on diagnostic criteria and long-term health risks related to polycystic ovary syndrome (PCOS). Hum Reprod 19: 41-47, 2004.

16. Kelly CC, Lyall H, Petrie JR, Gould GW, Connell JM and Sattar N: Low grade chronic inflammation in women with polycystic ovarian syndrome. J Clin Endocrinol Metab 86: 2453-2455, 2001.

17. Benson S, Janssen OE, Hahn S, Tan S, Dietz T, Mann K, Pleger K, Schedlowski M, Arck PC and Elsenbruch S: Obesity, depression, and chronic low-grade inflammation in women with polycystic ovary syndrome. Brain Behav Immun 22: 177-184, 2008.
18. Gonzalez F, Thusu K, Abdel-Rahman E, Prabhala A, Tomani M and Dandona P: Elevated serum levels of tumor necrosis factor alpha in normal-weight women with polycystic ovary syndrome. Metabolism 48: 437-441, 1999.

19. González F, Minium J, Rote NS and Kirwan JP: Hyperglycemia alters tumor necrosis factor-alpha release from mononuclear cells in women with polycystic ovary syndrome. J Clin Endocrinol Metab 90: 5336-5342,2005.

20. Wang CL, Hsieh MC, Hsin SC, Lin HY, Lin KD, Lo CS, Chen ZH and Shin SJ: The hOGG1 Ser326Cys gene polymorphism is associated with decreased insulin sensitivity in subjects with normal glucose tolerance. J Hum Genet 51: 124-128, 2006.

21. Xia Y, Che Y, Zhang X, Zhang C, Cao Y, Wang W, Xu P, Wu X, Yi L, Gao Q, et al: Polymorphic CAG repeat in the androgen receptor gene in polycystic ovary syndrome patients. Mol Med Rep 5: 1330-1334, 2012 .

22. Goodarzi MO, Dumesic DA, Chazenbalk G and Azziz R: Polycystic ovary syndrome: Etiology, pathogenesis and diagnosis. Nat Rev Endocrinol 7: 219-231, 2011.

23. Lunde O, Magnus P, Sandvik L and Høglo S: Familial clustering in the polycystic ovarian syndrome. Gynecol Obstet Invest 28: 23-30, 1989.

24. Hague WM, Adams J, Reeders ST, Peto TE and Jacobs HS: Familial polycystic ovaries: A genetic disease? Clin Endocrinol (Oxf) 29: 593-605, 1988.

25. Daimon M, Oizumi T, Toriyama S, Karasawa S, Jimbu Y, Wada K, Kameda W, Susa S, Muramatsu M, Kubota I, et al: Association of the Ser326Cys polymorphism in the OGG1 gene with type 2 DM. Biochem Biophys Res Commun 386: 26-29, 2009.

26. Lee KU: Oxidative stress markers in Korean subjects with insulin resistance syndrome. Diabetes Res Clin Pract 54 (Suppl 2): S29-S33, 2001.

27. Sentí M, Tomás M, Fitó M, Weinbrenner T, Covas MI, Sala J, Masiá R and Marrugat J: Antioxidant paraoxonase 1 activity in the metabolic syndrome. J Clin Endocrinol Metab 88: 5422-5426, 2003.

28. González F, Rote NS, Minium J and Kirwan JP: Reactive oxygen species-induced oxidative stress in the development of insulin resistance and hyperandrogenism in polycystic ovary syndrome. J Clin Endocrinol Metab 91: 336-340, 2006.

29. van der Velden AW and Thomas AA: The role of the 5 ' untranslated region of an mRNA in translation regulation during development. Int J Biochem Cell Biol 31: 87-106, 1999.

30. Bashirullah A, Cooperstock RL and Lipshitz HD: Spatial and temporal control of RNA stability. Proc Natl Acad Sci USA 98: 7025-7028, 2001

31. Lee MR, Kim SH, Cho HJ, Lee KY, Moon AR, Jeong HG, Lee JS, Hyun JW, Chung MH and You HJ: Transcription factors NF-YA regulate the induction of human OGG1 following DNA-alkylating agent methylmethane sulfonate (MMS) treatment. J Biol Chem 279: 9857-9866, 2004.

32. Youn CK, Kim SH, Lee DY, Song SH, Chang IY, Hyun JW, Chung $\mathrm{MH}$ and You HJ: Cadmium down-regulates human OGG1 through suppression of Sp1 activity. J Biol Chem 280: 25185-25195, 2005.

33. Liu X, Xiao N, Guo W, Wu Y, Cai Z, He Q, Zhang L, Chen X, Sun C, Wang J, et al: The hOGGl gene 5'-UTR variant c.-53G $>$ C contributes to the risk of gastric cancer but not colorectal cancer in the Chinese population: The functional variation of hOGG1 for gastric cancer risk. J Cancer Res Clin Oncol 137: 1477-1485, 2011.

34. Kim JC, Ka IH, Lee YM, Koo KH, Kim HC, Yu CS, Jang SJ, Kim YS, Lee HI and Lee KH: MYH, OGG1, MTH1, and APC alterations involved in the colorectal tumorigenesis of Korean patients with multiple adenomas. Virchows Arch 450: 311-319, 2007.

35. Yamane A, Kohno T, Ito K, Sunaga N, Aoki K, Yoshimura K, Murakami H, Nojima Y and Yokota J: Differential ability of polymorphic OGG1 proteins to suppress mutagenesis induced by 8-hydroxyguanine in human cell in vivo. Carcinogenesis 25 : 1689-1694, 2004

36. Hill JW and Evans MK: Dimerization and opposite base-dependent catalytic impairment of polymorphic S326C OGG1 glycosylase. Nucleic Acids Res 34: 1620-1632, 2006.

37. Xie H, Xia K, Rong H and Chen X: Genetic polymorphism in hOGG1 is associated with triple-negative breast cancer risk in Chinese Han women. Breast 22: 707-712, 2013.

38. Ding DP, Zhang Y and He XF: Lack of association between hOGG1 Ser326Cys polymorphism and breast cancer susceptibility in European population. Breast Cancer Res Treat 129: 1023-1026, 2011. 